\title{
Recirculated normal platelets adhere to surfaces coated with plasma from patients with immune thrombocytopenia
}

\author{
M. A. Azerad, J. Harsfalvi, H. Deckmyn, J. Vermylen, J. L. Michaux and M. F. Hoylaerts
}

(Received 23 April 1996; accepted in revised form 3 December 1996)

\begin{abstract}
Immune thrombocytopenic purpura (ITP) patients have characteristic anti-platelet antibodies in their circulation. To assess the interaction between such antibodies adhering on to a non-physiological surface and human platelets, normal anticoagulated blood was perfused over ITP patient plasma-coated surfaces in a parallel plate flow chamber. At $300 \mathrm{~s}^{-1}$, platelet adhesion to patient plasma-coated glass coverslips $(24.0 \pm 10 \%)$ was significantly higher than the adhesion to normal plasma-coated surfaces $(9.8 \pm 7 \%)$. When perfused at $1300 \mathrm{~s}^{-1}$, the adhesion to patient plasma- $(5.1 \pm 1.3 \%)$ and to normal plasma- $(2.5 \pm 1.2 \%)$ coated coverslips were significantly weaker. Furthermore, patient platelet binding depended on simultaneous contributions by antibodies and fibrinogen present on the plasma-coated surface, since adherence was antagonized both by normal immunoglobulins added to the perfusate, as well as by the anti-GPIIb/IIIa monoclonal antibody $16 \mathrm{~N} 7 \mathrm{C} 2$, which competes with fibrinogen for binding to its receptor on the platelet. Accordingly, platelet adhesion was only observed to coverslips coated with the plasma but not the serum of ITP patients. Hence, perfusion of normal platelets over surfaces coated with ITP patient plasma enables a functional assessment of the presence in this plasma of anti-platelet antibodies.
\end{abstract}

Key words: Immune thrombocytopenia, shear-induced platelet adhesion, anti-platelet antibodies, immune suppression, glycoprotein IIb/IIIa.

\section{Introduction}

Idiopathic thrombocytopenic purpura (ITP) is a hemorrhagic disorder defined by a low platelet count and a reduced platelet survival, in association with a normal or increased number of megakaryocytes in the bone marrow. The immune nature of this disorder, pointed out by Harrington and coworkers in 1951 is now well recognized. ${ }^{2}$ Platelet associated antibodies are mostly directed against the platelet receptors GPIIb/IIla, the GPIb-IX complex and less frequently against GPV or GPIa/IIa.,4 Anti-platelet antibodies not only enhance the turnover of platelets but may also cause their activation. ${ }^{5}$

Recent studies have shown that even the simple coating of microtiter plate surfaces with nonfractionated plasma sufficed to induce platelet adhe- sion to these surfaces, ${ }^{6,7}$ This adhesion promoted under static conditions depends primarily on interactions between coated fibrinogen and platelet GPIIb/IIIa, 7,8 whereas immunoglobulins do not participate in the adhesion of resting platelets. ${ }^{8}$

Perfusion chambers first developed by Baumgartner and Sakariassen, 9,10 under flow conditions, allow the exploration of platelet interactions with surfaces containing insolubilized ligands. These studies have highlighted the importance of several platelet receptors, especially GPIb and GPIIb/IIIa in the adhesion of platelets to vessel wall components.

When plasma is allowed to coat on foreign surfaces, such as vascular protheses, platelets can attach and subsequently spread on these surfaces, thus

M. A. Azerad and J. L. Michaux are with the Service d'Hematologie Cliniques Universitaires St Luc, Avenue d'Hippocrate 10, 1200 Bruxelles, Belginm; J. Harsfalvi is with the Department of Medicine, University Medical School Debrecen, Hungary; H. Deckmyn is with the Laboratory for Thrombosis, IRC, KU Leuven, Campus Kortriik, Belgium; J. Vermylen is with the Center for Molecular and Vascular Biology, KU Lewven, Belgium. Address correspondence to: M. F. Hoylaerts, Center for Molecular and Vascular Biology, University of Lewven, Campus Gasthuisberg, Herestraat 49, B-3000 Lewven, Belgium. Tel: (+32) 1634 5791; Fax: (+32) 16345990. 
initiating thrombus formation. In view of this adhesion, in the present study we have investigated how shear forces affect the interaction between platelets and surfaces coated with normal plasma or with ITP plasma proteins, amongst which antiplatelet membrane protein antibodies. Furthermore, we have used this platelet adhesion assay to in vitro investigate whether immunoglobulin addition to circulating blood would neutralize the antibody dependent platelet adhesion.

\section{Patients and methods}

\section{Patient inclusion}

Nine consecutive patients with ITP were included in the study after informed consent. The diagnosis was based on the following criteria: thrombocytopenia with a platelet count below $150 \times 10^{9} / 1$, normal or increased number of bone marrow megakaryocytes, shortened platelet survival, absence of other causes of increased platelet destruction, and finally negative tests for lupus, hepatitis or HIV antibodies. Antiplatelet antibodies were not considered an inclusion criterion. Table 1 summarizes the clinical data for the patients included in the study.

\section{Perfusion technique}

A parallel plate perfusion chamber as previously described by Sakariassen et al. ${ }^{10}$ was used to study the effect of immobilizing plasma or serum proteins from ITP patients on the degree of adhesion of platelets present in circulating normal whole blood. Ten $\mathrm{ml}$ blood from healthy volunteers not taking any medication compromising platelet function or coagulation during the week preceding the study, was collected by clean venipuncture into $0.1 \mathrm{vol}$ $110 \mathrm{mM}$ trisodium citrate. To avoid any incompatibility related to blood group type or Rhesus system, blood was only taken from normal subjects with blood group 0 .

Platelet-poor plasma (PPP) was obtained by centrifugation of whole blood for $15 \mathrm{~min}$ at $3000 \times g$. Sera were prepared from non-anticoagulated whole blood after incubation at $37^{\circ} \mathrm{C}$ for $1 \mathrm{~h}$. Supernatant sera were centrifuged and stored at $-20^{\circ} \mathrm{C}$ until use. Perfusion was carried out at $37^{\circ} \mathrm{C}$ at a constant shear stress of $300 \mathrm{~s}^{-1}$ to mimic blood flow in the larger arterial vascular bed and at $1300 \mathrm{~s}^{-1}$ to reproduce the shear forces encountered in arterioles and stenotic areas.

Glass coverslips were coated overnight with $100 \mu \mathrm{l}$ of serum or PPP in a humidified chamber. In order to investigate whether as a consequence of the Vroman effect, ${ }^{11,12}$ a modification with time of the plasma protein composition on the coverslip would lead to alterations in the extent of platelet adherence, coverslips were coated for various time intervals ( $30 \mathrm{~min}$ to $20 \mathrm{~h}$ at $4^{\circ} \mathrm{C}$ ). Normal or ITP serum or plasma-coated coverslips were then perfused and recirculated for $5 \mathrm{~min}$ with $10 \mathrm{ml}$ of citrated whole blood derived from normal subjects (group $\mathrm{O} \mathrm{Rh}^{+}$) and prewarmed at $37^{\circ} \mathrm{C}$ for $5 \mathrm{~min}$. Coverslips were removed from the perfusion chamber, rinsed in HEPES buffer and fixed with 1\% glutaraldehyde in PBS prior to staining with May-Grünwald Giemsa.

The disappearance of single platelets (SPD) was calculated using the following formula: SPD $=$ \{(final platelet count in EDTA) - (final platelet count in Formol) $\} /$ (initial platelet count in EDTA). The platelet count of the blood samples was determined before and after each perfusion with a

Table 1. Patient characteristics of ITP patients included in the study

\begin{tabular}{lcccccl}
\hline $\begin{array}{l}\text { Patient } \\
\text { number }\end{array}$ & Sex & $\begin{array}{c}\text { Age } \\
\text { (years) }\end{array}$ & $\begin{array}{c}\text { Duration } \\
\text { disease } \\
\text { (months) }\end{array}$ & $\begin{array}{c}\text { Platelet } \\
\text { count } \\
(\text { per } \mu \mathrm{l}) \\
\times 10^{9} / 1\end{array}$ & $\begin{array}{c}\text { Fibrinogen } \\
(\mathrm{g} / \mathrm{l})\end{array}$ & Treatment \\
\hline 1 & $\mathrm{M}$ & 65 & 1 & 71 & 1.97 & $\mathrm{G}$ \\
2 & $\mathrm{M}$ & 23 & 48 & 8 & 3.77 & $\mathrm{c}+\mathrm{S}+\mathrm{Cy}$ \\
3 & $\mathrm{~F}$ & 24 & 1 & 22 & 3.21 & - \\
4 & $\mathrm{~F}$ & 45 & 156 & 9 & 2.9 & $\mathrm{c}$ \\
5 & $\mathrm{~F}$ & 74 & 2 & 116 & 2.29 & $\mathrm{c}$ \\
6 & $\mathrm{~F}$ & 41 & $<1$ & 2 & 2.0 & - \\
7 & $\mathrm{~F}$ & 42 & 120 & 118 & 1.75 & $\mathrm{G}$ \\
8 & $\mathrm{~F}$ & 21 & 132 & 80 & 3.46 & $\mathrm{c}+\mathrm{S}$ \\
9 & $\mathrm{~F}$ & 21 & 16 & 25 & 1.58 & $\mathrm{C}+\mathrm{G}+\mathrm{S}$ \\
\hline
\end{tabular}

G: Gammaglobulins; C: corticoids high dose $(>0.5 \mathrm{mg} / \mathrm{kg})$; $c$ : corticoids low dose; Cy: cyclosporin; S: splenectomy. 
Cell-Dyn 610 (Sequoia Turner Corporation, Mountain View, CA).

Quantitation of platelet adhesion was done by analysis of the surface covered using en face light microscopy (Dialux $20 \mathrm{~EB}$, E. Leitz GmbH, Wetzlar, Germany) at a low magnification $(\times 40)^{9}$ and the 'TCL-Image' image processing software (Multihouse TSI, Amsterdam, the Netherlands).

\section{Kinetics of fibrinogen and immunoglobulin coating}

To investigate whether the amount of fibrinogen and immunoglobulin deposited on the glass coverslip would vary as a function of time, in agreement with the Vroman effect, ${ }^{11,12}$ coverslips were coated in a humidified chamber with normal plasma $(100 \mu \mathrm{l})$ and IT'P patient plasma at $4^{\circ} \mathrm{C}$ for $30 \mathrm{~min}$ and for 2, 4, 6 and $20 \mathrm{~h}$. The coated coverslips were then rinsed with $10 \mathrm{mM}$ HEPES buffer, $\mathrm{pH} 7.35$, containing $145 \mathrm{mM} \mathrm{NaCl}$ and non-occupied sites were saturated with 1\% BSA dissolved in PBS, following a classical ELISA approach. Coverslips were then incubated overnight at $4^{\circ} \mathrm{C}$ with either goat-anti-human fibrinogen antibodies conjugated to horseradish peroxidase (HRP; Dakopatts) or with a monoclonal anti-human Ig antibody-HRP conjugate (Southern Biotechnology Ass., Inc., Birmingham, UK). Finally, the coverslips were rinsed and bound peroxidase was detected via staining with orthophenylenediamine and photometric detection at $492 \mathrm{~nm}$.

\section{Mechanism of platelet adhesion}

In order to further assess the role of platelet GPIIb/ IIIa in the adhesion of platelets to the coated surfaces, perfusions were performed in the presence of the monoclonal anti-GPIIb/IIIa antibody 16 N7C2 $(30 \mu \mathrm{g} / \mathrm{ml})$ that competitively blocks fibrinogen binding to human GPIb/IIIa. ${ }^{13}$ This antibody was added to the perfusate $30 \mathrm{~min}$ prior to the perfusion.

In view of the postulated presence of anti-idiotypic antibodies in pooled human immunoglobulins, capable of neutralizing anti-platelet antibodies, ${ }^{14}$ pooled lyophilized immunoglobulins (Ig Sandoglobulins, Basle, Switzerland) were dissolved in the anticoagulated blood to $6 \mathrm{mg} / \mathrm{ml}$ at room temperature for up to $1 \mathrm{~h}$ before perfusion over normal or ITP patient plasma-coated surfaces.

\section{Results}

Time-dependence of fibrinogen and immunoglobulin coating

A kinetic analysis of the amounts of fibrinogen and immunoglobulins adhering during the coating of coverslips with plasma, was suggestive of a timedependent decrease of the levels of adhering immunoglobulins at short incubation times up to $4 \mathrm{~h}$, followed by a sharp rise after $6 \mathrm{~h}$. Although this increase was not significant in the case of the normal plasma immunoglobulin coatings, the patient plasma immunoglobulin peak after $6 \mathrm{~h}$ of coating, reached statistical significance $(P<0.05)$ when compared with the adhering immunoglobulin levels after overnight coatings (Table 2). The fibrinogen levels on the contrary fluctuated less (Table 2). To further investigate whether this change in protein composition would affect the degree of platelet adhesion, anticoagulated blood was perfused over coverslips coated with normal and ITP plasma for various time intervals. No significant differences were observed however between the surface coverages between coating times of $2,4,6,8$ and $20 \mathrm{~h}$. Therefore, the remainder of the experiments were conducted with coverslips coated overnight at $4^{\circ} \mathrm{C}$.

Table 2. Variation with time of the levels of fibrinogen and immunoglobulin binding to glass coverslips during the coating at $4^{\circ} \mathrm{C}$ of normal and patient plasma, analysed via peroxidase coupled antibody binding and light absorption measurements ${ }^{*}$

\begin{tabular}{|c|c|c|c|c|}
\hline \multirow[b]{2}{*}{$\begin{array}{l}\text { Time } \\
\text { (h) }\end{array}$} & \multicolumn{2}{|c|}{ Patient plasma } & \multicolumn{2}{|c|}{ Normal plasma } \\
\hline & $\begin{array}{c}\text { Fibrinogen } \\
\left(\mathrm{A}_{492 \mathrm{~m} n}\right)\end{array}$ & $\begin{array}{l}\text { Immunoglobulin } \\
\qquad\left(A_{492 n m}\right)\end{array}$ & $\begin{array}{l}\text { Fibrinogen } \\
\left(A_{+92 \mathrm{am}}\right)\end{array}$ & $\begin{array}{c}\text { Immunoglobulin } \\
\left(\mathrm{A}_{442 \mathrm{~m}}\right)\end{array}$ \\
\hline 0.5 & $0.240 \pm 0.142$ & $0.769 \pm 0.545$ & $0.343 \pm 0.063$ & $0.494 \pm 0.489$ \\
\hline 2 & $0.210 \pm 0.038$ & $0.689 \pm 0.157$ & $0.237 \pm 0.129$ & $0.460 \pm 0.272$ \\
\hline 4 & $0.303 \pm 0.179$ & $0.554 \pm 0.083$ & $0.261 \pm 0.173$ & $0.339 \pm 0.194$ \\
\hline 6 & $0.250 \pm 0.089$ & $2.002 \pm 0.814$ & $0.169 \pm 0.017$ & $0.644 \pm 0.464$ \\
\hline 20 & $0.342 \pm 0.234$ & $0.374 \pm 0.051$ & $0.185 \pm 0.152$ & $0.292 \pm 0.110$ \\
\hline
\end{tabular}

${ }^{*}$ Results are the mean \pm SD for the binding of three normal and three patient plasmas. 


\section{Effect of shear forces on platelet adhesion}

The perfusion at $300 \mathrm{~s}^{-1}$ of anticoagulated blood derived from normal donors over coverslips coated overnight with normal plasma, resulted in the weak adhesion of irregularly scattered platelets only, the adhesion being somewhat increased when plasma was used from a pool of healthy volunteers. Adhering platelets were found as single cells or as small aggregates consisting of a few platelets only (Figure 1a). Morphologically, these platelets were activated, as judged from their irregular shape and spreading. In contrast, when normal anticoagulated blood was perfused over coverslips coated overnight with plasma derived from ITP patients, a much stronger and more homogeneous platelet adhesion was observed (Figure 1b), with evidence of occasional platelet spreading but especially of the presence of large aggregates.

When perfusions were performed at $1300 \mathrm{~s}^{-1}$, platelet adhesion to normal plasma-coated surfaces was reduced to a few single platelets (Figure 1c), whereas the perfusion over ITP plasma-coated surfaces, in addition to the presence of primarily single platelets, still resulted in the appearance of larger aggregates (Figure 1d).

Although large interindividual variations were observed for different patient plasmas, the mean platelet surface coverage calculated for perfusions at $300 \mathrm{~s}^{-1}$ over ITP patient plasmas was significantly increased $(24.0 \pm 10.4 \%)$ in comparison with the surface coverage of $9.8 \pm 7 \%$ derived for perfusions over normal plasma $(P<0.05)$. However, when perfusions were performed over patient plasma-

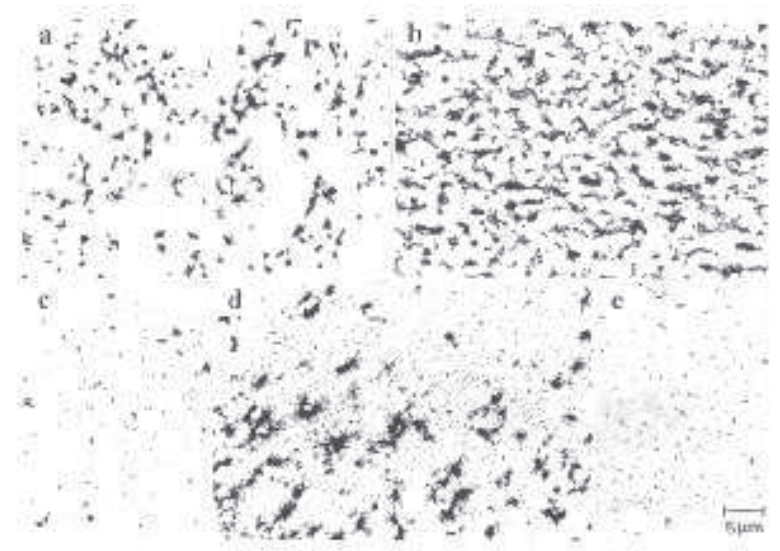

Figure 1. Platelet adhesion after perfusion of normal anticoagulated blood over glass coverslips coated with normal plasma (A, C), or ITP patient plasmas (B, D and E), perfused at $300 \mathrm{~s}^{-1}$ $(A, B, E)$ or at $1300 \mathrm{~s}^{-1}(C, D)$, in the absence $(A-D)$ or in the presence of antibody $16 \mathrm{N7C2}$ (E). Scale bars represent $20 \mathrm{~mm}$. coated surfaces at $1300 \mathrm{~s}^{-1}$, a significantly weaker platelet adhesion was observed $(5.1 \pm 1.3 \%)$. For perfusions over normal plasma coated surfaces, at $1300 \mathrm{~s}^{-1}$ even lower surface coverages were found $(2.5 \pm 1.2 \%)$.

Platelet numbers present in the anticoagulated blood prior to perfusion ranged from 200 to $300 \times 10^{9} /$ l. After the perfusion over the plasmacoated surfaces, these numbers slightly dropped. Calculation of the average SPD values for a total of 31 different runs yielded a mean index for the disappearance of platelets equal to $15.8 \pm 8.3 \%$.

\section{Role of fibrinogen-GpIIb/IIIa axis in the adhesion}

When perfusions were performed on surfaces coated with serum, no platelet adhesion was observed, neither for perfusions over ITP patient sera-coated surfaces nor for perfusions over normal serumcoated surfaces $(0.10 \pm 0.03 \%)$. Since these experiments suggested the involvement of coated fibrinogen, perfusions over plasma-coated surfaces were also performed in the presence of the anti-GpIIb/ IIIa monoclonal antibody $16 \mathrm{~N} 7 \mathrm{C} 2$; this antibody $(30 \mu \mathrm{g} / \mathrm{ml})$ indeed blocked platelet adhesion completely when perfused at $300 \mathrm{~s}^{-1}$ over IT'P patientcoated plasma, i.e. the surface coverage dropped from an average $16 \%$ in the absence of $16 \mathrm{~N} 7 \mathrm{C} 2$ to $0.1 \%$ in its presence (Figure $1 \mathrm{e}$ ).

\section{Neutralization of adhesion by added immunoglobulins}

Pooled lyophilized human immunoglobulins dissolved in the perfusate to $6 \mathrm{mg} / \mathrm{ml}$, had a small effect on the weak surface coverage observed during perfusions over normal plasma-coated coverslips, causing a non-significant drop from $3.7 \pm 3.1$ to $1.4 \pm 1.4 \%(n=3)$. However, immunoglobulin addition reduced the more prominent platelet surface coverage found during perfusions over ITP plasmacoated surfaces significantly from $13.1 \pm 6.4 \%$ to $1.9 \pm 0.97 \%(n=3, P<0.05)$. Immunoglobulin addition to the anticoagulated blood at higher concentrations $(12 \mathrm{mg} / \mathrm{ml})$ was associated with a drop in platelet numbers during the subsequent perfusion and was not further analyzed. Control experiments in which coverslips were directly coated overnight with gammaglobulins and perfused with normal anticoagulated blood did not show any platelet adhesion to such coverslips (not shown).

\section{Discussion}

The existence of anti-platelet antibodies in immune thrombocytopenic purpura patients is evident, but 
the pathogenic role of such antibodies remains unclear. A good correlation was reported between the levels of platelet associated IgG and the clinical evolution or response to treatment in the acute and chronic ITP. ${ }^{15,16}$ However, despite their very low platelet counts, ITP patients usually suffer few bleeding events which complicates an assessment of their bleeding risk.

In the present study, we used an in vitro perfusion system to functionally analyse the presence of antiplatelet antibodies in the plasma of ITP patients. We found that normal platelets consistently adhered to ITP plasma-coated coverslips to a higher degree than to normal plasma-coated surfaces suggestive of an anti-platelet antibody mediated adhesion of platelets to ITP plasma-coated surfaces. Even though variations of antibody binding to the coverslip were noted with time, these variations were not associated with a significant reduction in the degree of adhesion, however, the inhibition of platelet adhesion to ITP plasma-coated surfaces by immunoglobulins added to the perfusate nevertheless substantiates a role for anti-platelet antibodies during platelet recruitment. Indeed, it has been postulated that anti-idiotype antibodies present in pools of immunoglobulins may neutralize the anti-platelet antibodies ${ }^{14}$ and hence reduce the adherence of circulating platelets.

However, since platelet adhesion was entirely lacking when ITP serum was used for the coating, the observed platelet adhesion was not exclusively mediated by anti-platelet antibodies but also depended on immobilized fibrinogen, a conclusion further supported by our finding that an antibody, antagonizing fibrinogen binding to its receptor on platelets (GPIIb/IIIa), completely prevented platelet adhesion to ITP plasma-coated coverslips. Thus, our findings confirm under conditions of flow that the adhesion of platelets to plasma protein-coated surfaces occurs via GPIIb/IIIa interactions with coated fibrinogen, a conclusion further supported by the observed platelet spreading, a typical property of platelet interactions with coated fibrinogen. Our data also show that the presence in the circulation of anti-platelet antigen antibodies aggravates platelet adhesion to foreign surfaces, further increasing the risk for platelet aggregation and thrombosis on such surfaces. These phenomena are more evident at shear forces encountered in the larger arteries (0.2$0.5 \mathrm{~cm}$ ), i.e. in those arteries subject to vascular replacement surgery than at higher shear forces such as encountered in smaller arteries. The weaker interactions at high shear forces can be explained by the contribution to the platelet binding of the GPIIb/
Illa-fibrinogen interaction, an interaction which is not sufficiently strong to resist high shear forces. ${ }^{17}$

In conclusion, our data show that a brief exposure of flowing normal blood to coverslips coated with plasma but not with serum from ITP patients, induced antibody dependent platelet adhesion. Further investigations will be required to define whether the in vitro perfusion of normal platelets over IT'P plasma-coated surfaces will constitute a valuable functional test to ex vivo assess the presence of anti-platelet antibodies in the plasma of ITP patients and to monitor their disappearance on treatment.

Acknowledgements - The present study was supported by the research grant IUAP35 and the research grant 3.0030 .90 from the Belgian NFWO. J.V. is holder of the 'Dr J. Choay Chair in Haemostasis Research'.

\section{References}

1. Bellucci S. Autoimmune thrombocytopenias. Bailliere's Clin Haematol 1989; 2: 695-718.

2. Harrington WJ, Minnich V, Hollingsworth PJ, Moore CV. Demonstration of a thrombocytopenic factor in the blood of patients with thrombocytopenic purpura. J Lab Clin Med 1951; 38: 1-9.

3. Kiefel V, Santoso S, Weisheit M, Mueller-Eckhardt C. Monoclonal antibody-specific immobilization of platelet antigens (MAIPA): a new tool for the identification. of platelet reactive antibodies. Blood 1987; 70: 1722 1726.

4. Kokawa T, Nomura S, Yanabu M, Yasunaga K. Detection of platelet antigen for platelet antibodies in idiopathic thrombocytopenic purpura by flow cytometry, antigen capture ELISA and immunoblotting: a comparative study. Eur J Hematol 1993; 50: 74-80.

5. Deckmyn H, de Reys S. Functional effects of human antiplatelet antibodies. Semin Thromb Hemost 1995; 21: $46-59$.

6. Bellavite P, Andrioli G, Guzzo P, et al. A colorimetric method for the measurement of platelet adhesion in microtiter plates. Anal Biochem 1994; 216: 444-450.

7. Di Fazio LT, Stratoulias C, Greco RS, Haimovich B. Multiple surface receptors mediate platelet adhesion to surfaces coated with plasma proteins. J Surg Res 1994; 57: $133-137$.

8. Nagai H, Handa M, Kawai Y, Watanabe K, Ikeda Y. Evidence that plasma fibrinogen and platelet membrane GPIIb/IIIa are involved in the adhesion of platelets to an artificial surface exposed to plasma. Thromb Res 1993; 71: 467-477.

9. Baumgartner HR, Muggli R, Tschopp TB, Turitto T. Platelet adhesion, release and aggregation in flowing blood: effects of surface properties and platelet function. Thromb Haemost 1976; 35: 124-138.

10. Sakariassen KS, Aarts PAMM, de Groot PG, Houdijk WPM, Sixma JJ. A perfusion chamber developed to 
investigate platelet interaction in flowing blood with human vessel wall cells, their extracellular matrix, and purified components. J Lab Clin Med 1983; 102: 522535.

11. Vroman L, Adams AL. Identification of rapid changes at plasma-solid interfaces. J Biomed Mater Res 1969; 3: 43-67.

12. Vroman L. The life of an artificial device in contact with blood: initial events and their effects on its final state. Bull NY Acad Med 1988; 64: 352-357.

13. Deckmyn H, Stanssens P, Hoet B, et al. An echistatin-like Arg-Gly-Asp(RGD)-containing sequence in the heavy chain CDR3 of a murine monoclonal antibody that inhibits human platelet glycoprotein GPIIb/IIla function. Br J Haematol 1994; 87: $562-$ 571.
14. Berchtold P, Dale GL, Tani P, McMillan R. Inhibition of autoantibody binding to platelet glycoprotein $\mathrm{IIb} /$ III a by antiidiotypic antibodies in intravenous gammaglobulin. Blood 1989; 74: 2414-2417.

15. Slack SM, Weiss HJ, Lages B, Turitto VT. Mathematical analysis of bleeding time data in patients with platelet disorders and von Willebrand's disease. Platelets 1995; 6: 169-175.

16. Berchtold P, Wenger M. Autoantibodies against platelet glycoprotein in autoimmune thrombocytopenic purpura: their clinical significance and response to treatment. Blood 1993; 81: 1246-1250.

17. Savage B, Saldivar E, Ruggeri ZM. Initiation of platelet adhesion by arrest onto fibrinogen or translocation on von Willebrand factor. Cell 1996; 84: 289 297. 